\title{
Agrivoltaics for Doubling of Income Through Simultaneous Crop and Energy Production in Same Land
}

\section{MK Ghosal*}

Professor, Department of Farm Machinery and Power, Odisha University of Agriculture and Technology, Bhubaneswar, Odisha, India

*Corresponding Author: MK Ghosal, Professor, Department of Farm Machinery and Power, Odisha University of Agriculture and Technology, Bhubaneswar, Odisha, India.

Agrivoltaic system is a concept of growing crops and generating PV-based electricity from the same land and time and is one of the future of the land use systems from where both food and energy can be produced. Development of agrivoltaic system is based on dual uses of land for simultaneous crop and energy production. The concept is originated from the same approach of agroforestry in which productivity of the land is increased by following intercropping among the trees. By adopting such system in agricultural land, farmers can earn income from their land through sale of PV generated electricity along with the crop production. Ideally, crops for these sites should be such that it should not be tall (preferably less than $50 \mathrm{~cm}$ ), spreading type and do not interfere in any way with the functional efficiency of solar PV modules. As the PV system creates shading for the crops grown below the pillars of its structure, the sensitivity of the crop yield with respect to the shading effect needs to be examined. The crop selection, mounting height, optimal tilt angle, solar irradiation and local climate play the key role in the optimal selection of PV system geometry for an agrivoltaic system. Solar PV electricity is a promising source of energy and has the greatest potential for India located in the tropical zone where there is the abundant availability sunlight throughout the year. To meet the national solar mission target of 60 GW PV based electricity generation by 2025 in India, total area of land, required, is about 1.2 lakh ha or 1,200 sq. km @ 2 ha area per MW. The required area for this demand cannot be only met from the building integrated rooftop based PV system due to increasing number of buildings in urban areas and the rest can be met with land-based PV farms. Use of the large tracts of land for solar farms will increase competition of land resources for crop production as the demands of food and energy are increasing day by day due to the growing population. The output of the PV module also depends on the operating temperature of a PV module, which is dependent on the ambient temperature, wind speed and solar radiation. Hence, it is proposed to study the feasibility of the system for a particular climatic condition. In addition, the agrivoltaic system can also act as a power source for operating irrigation pumps on standalone manner. Installation of such systems in farmers' field may fetch additional income from sale of electricity in addition to crop production. Cultivating crops in areas below PV array has the additional advantage of reducing heat load on bottom surface of solar panel by modifying the microclimatic conditions and thus helps in generating optimum electric output. Agrivoltaic systems are reported to be highly productive, with increase in the overall land productivity as high as $60-70 \%$. Around $30 \%$ of area in agrivoltaic system is under shaded condition which can be utilized by cultivating shade tolerant crops. Hence, around $90 \%$ of the total area of the land can be made cultivable except the area which is occupied by the pillars of the solar PV system. Annual income from PV generated electricity has been estimated as Rs. 6.75 lakhs per half acre $\left(2000 \mathrm{~m}^{2}\right)$ of land, whereas cost involved for installation of such system is 40.00 lakhs and thus the payback period of the system is about 5.00 years. Findings of the study would provide a new dimension for dual uses of land in doubling the farmers' income at the individual level. The popularization in the use of solar PV electricity in a wider scale would reduce the dependence of fossil fuel and hence, resulting into its positive effect in the society for the sustenance of environment. Propagation of this practice would strengthen the farmers in enhancing their income both from the generated electricity and cultivated crop and also to empower the rural unemployed youths to take up agri-entrepreneurship as 
their avocation. Agrivoltaic system is therefore technically feasible, economically viable and environment-friendly for ensuring income even if there is crop failure due to adverse weather conditions.

Volume 5 Issue 7 July 2021

(C) All rights are reserved by MK Ghosal. 